(Guy's Hospital Reports, vol. iii, p. 9o) and Dr. Ogle connect purpura with a diseased condition of the spleen. The cutaneous capillaries have been also examined; and though, in one case, Dr. Tilbury Fox found them undergoing a lardaceous change, the patient had a history of syphilis, and other observers have found nothing wrong with them.

Dr. Richardson has started (Lancet, 1874, vol. ii, p. 729) a hypothesis accounting for the varieties of purpura, and has defined three forms, each with a distinct pathology, etiology, and treatment: $(a)$ aqueous; $(b)$ saline; and $(c)$ vascular-referring thereby to the altered condition of the blood, its salts, and the walls of the vessels.

My own view as to the pathology of purpura is that the nervous system is primarily at fault ; and that, through the influence of the vasomotor system, the blood and the capillaries are secondarily affected. The following reasons occur to me as justifying such a conclusion.

1. The majority of the cases of purpura present a history pointing to some nerve-waste, such as over-exercise, fatigue, and mental emotion.

2. The prominent symptom at the onset of the disease, long prior to the occurrence of cutaneous hæmorrhages, throughout its course, and for some time after the cessation of all bleeding, is that of exhaustion, muscular weakness, and fatigue; and this holds good, whether or not the attack be accompanied with pyrexia.

3. The analogy which exists in the acknowledged influence of the sympathetic nerve over cutaneous eruptions, such as erythema and herpes, and the altered pigmentation in pregnancy, leucoderma, and morbus Addisonii.

4. The symmetry of the eruption; the rapid manner in which purpura at times makes its appearance; and the still more remarkable way in which further hæmorrhages are abruptly arrested while the patient is exposed to the same circumstances, hygienic and dietetic, and while the constitution of the blood, it must be acknowledged, can hardly have undergone any alteration.

5. The close connection between disease of the cerebro-spinal centres and purpura, such as was manifested in that malignant purpuric fever (Stokes), or cerebro-spinal fever, which, as an epidemic, visited Dublin in $1868: 9$, the fell influence of which still clings round our patients, and, complicating nearly every disease of a febrile type, renders prognosis most difficult and treatment too often futile.

In this view of the neurotic origin of purpura, I find I am not quite alone; for, though all the writers on purpura whom I have consultedand they are not a few-seem never to allude to this possible influence of the sympathetic as a factor of the pathology of this obscure disease, Dr. Andrew Minich (Philadelphia Medical Times, 1875, quoted in the London Medical Record), dismissing the hypothesis that the disease rests upon a change in the blood, or is due to a fatty degeneration of the capillaries, is of opinion that the real patholngy is vaso-motor paralysis.

The cases I have described present some features deserving, I believe, a passing notice. Case I may be termed an extreme instance of the variety termed peliosis rheumatica. In it, not only were rheumatic pains much complained of (as I mentioned, it was for the rheumatism the patient sought relief), but there was great effusion into the right knee, and to a less extent into the left. There was also effusion under the periosteum of the left tibia. That the former was but serum I have little doubt, judging from the rapidity with which it was absorbed; but the latter was, I suspect, blood, since for fully ten days the localised swelling of the left tibia was evident. The extent of the cutaneous hæmorrhage was remarkable; and the appearance of the right leg so closely resembled that of a limb which had been subjected to the worst possible injury short of fracture, that one of my surgical colleagues, who saw it with me, said it might,readily pass, in the absence of any history, for a most severe contusion of the leg and knee.

It is further deserving of note, as it proved an exception to the statement of Hebra (page 423), that peliosis rheumatica occurs generally in the strong and healthy, in males between twenty and thirty years old, never in children or aged persons.

Case III belongs to the same category as Case I--namely, the rheumatic variety-and presents the comparatively unusual symptom of the purpura engaging the forearms as well as the legs. Niemeyer, indeed, states that peliosis rheumatica is only met on the lower extremities. It contrasts with Case I, moreover, by the pains being more confined to the muscles. Hence Case III might be considered as purpura with rheumatic pains, and Case I purpura with rheumatism of the joints.

I have described these two cases under the generic term of purpura hæmorrhagica for reasons already given, and because in each case the bleeding was not confined to the cutaneous surface. According to Hebra, the occurrence of hæmorrhage from the mucous tracts marks the difference between purpura simplex and purpura hæmorrhagica. There can, however, be no doubt, looking to the prominence of the symptoms, that they both deserve to be placed under the term purpura rheumatica.
Believing, as I do, in the nervous origin of purpura, I am not prepared to consider this yariety, as Wunderlich holds surch to be, to be purpura with the rheumatic phenomena grafted on as epiphenomena; nor do I conform to the view ably put forward by Dr. Southey (Lancet, 1877, vol. ii, p. 6), that the peliosis rheumatica of Schönlein is nothing but purpura occurring in the persons subjects of chronic nephritis, or in whom, sooner or later, it will be complicated by acute renal affections.

There is much in the published reports on purpura, and our French confrères have contributed largely to the literature on the subject, to justify the views, adopted generally by French writers, that peliosis rheumatica is really a variety of, and is identical with, erythema nodosum. Dr. Robert Liveing (Lancet, 1877, vol. ii, p. 307) advocates this theory. I have myself met with several cases where the rheumatic symptoms followed upon the erythema; but Cases I and III cannot, I think, come under such a definition, inasmuch as in each case, and particularly Case I, the rheumatic pains preceded the cutaneous hæemorrhages by a considerable interval-by two weeks in Case I, and two days in Case III.

In conclusion as to treatment, so far as the evidence of the cases I have described warrants one in drawing any inference, I would say that the best results are to be looked for by the employment during the attack of physiological medicines, such as ergot and belladonna, especially ergot; since, by their action on the capillaries through the vaso-motor nerves, vaso-motor spasm is induced, and thus the tendency to transudation of the blood-corpuscles through their walls can best be kept in check. Perchloride of iron certainly did not in my hands produce the good effects that might be expected of it, although it has been strongly recommended by some, including Neumann.

Since I prepared this paper, I find that ergot has produced the best results at the hands of others, and is quoted by Neumann as advocated by Henoch and Bauer. In addition, I would mention that Robert Campbell (Ncw York Medical Journal, December 1878) treated cases with it, administered internally; and Dr. Andrew Minich found the profuse bleedings in a case of severe purpura hæmorrhagica to be arrested by the hypodermic injection of ergotin.

In cases of peliosis rheumatica, Neumann lays the greatest stress upon the patient assuming the horizontal posture, and maintaining it for some time after the eruption has disappeared. Niemeyer also approves this treatment. I cannot, however, give much credit to it, since the patient in Case I, who was confined to bed for nearly a fortnight before admis. sion to hospital, showed no evidence that she had derived any benefit therefrom; and the subject of Case III, who never remained in bed more than one day, nor more than three in the house, made a rapid and good recovery, so far as the cutaneous hæmorrhages were concerned.

As soon as the acute symptoms of purpura hæmorrhagica abate, I think the best treatment seems to be that by mineral acids and bark-a treatment as old as the seventeenth century, when it was recommended by Werholf in morbus maculosus. Little good is to be looked for from the antiscorbutic diet, as vegetables and lemon-juice have no influence whatever in purpura.

\section{NOTES ON THE TREATMENT OF RINGWORM.}

By WYNDHAM COTTLE, M.A., M.B.Oxon., F.R.C.S., M.R.C.P., Senior Assistant-Surgeon to the Hospital for Diseases of the Skin, Blackfriars.

FEw cutaneous diseases have been the subject of more numerous and varied methods of treatment than ringworm. Many of these plans are difficult or painful in their application, and all of them frequently fail in cases of difficulty. Impressed with the unsatisfactory nature of the means at our command for combating this disease, I have long been looking for some manageable and reliable mode of procedure. I was early struck with the ready curability of ringworm in infants and when situated on parts of the body unoccupied by a vigorous hair-growth, and I took the difference to be that, in the more hirsute regions, the materies morbi had invaded and found shelter in the deep hair-follicles, etc., and that the difficulty we experience in eradicating it consists in our inability to attack it in itsl air. Observation has taught me that ringworm, even of the most obstinate character and in hair-clothed parts, rarely if ever survives suppuration in its site. We see this when suppurative inflam. mation has been set up or kerion has supervened. I think this beneficial action results from the presence of some of the inflammatory products affecting the disease in its deep follicular seats, and perhaps from the admission of some of the remedfal agents that may be simultaneously applied.

Keeping these points in view, I have endeavoured artificially to imitate this curative action of nature. In practice, I found it no easy 
matter to accomplish. I endeavoured to find some substance inimical to fungoid growth and also capable of exercising the required action on the skin.

My earlier attempts were made with the sulpho-carbolates of barium and zinc, with which I obtained some success. I used the sulphocarbolate of barium in the form of an ointment, thirty grains to an ounce of lard, and the zinc salt as a lotion, twenty-five grains to an ounce of water. The suppuration that I succeeded in producing by by means of sulpho-carbolate of barium was often slow in developing itself, and occasionally no such effect followed its use. After making trial of various agents, I have obtained the best results by painting the most obstinately affected portions of the scalp with linimentum crotonis and directing the subsequent frequent use of an ointment or lotion of salicylic acid. One application of the croton oil usually suffices to produce a copious pustular rash over the parts with which it is brought in contact. If it fail to do so, the application should be repeated. An ointment of ten to forty grains of salicylic acid to the ounce of the base selected should then be rubbed over the scalp twice or thrice daily. The strength, frequency, and vigour of the application should be proportioned to the inflammatory effect that results. All crusts, scales, and diseased hairs, should be removed as speedily as possible. Though this mode of treatment is neither suitable to every case, nor universally successful, it possesses some advantages. I. The croton oil liniment gives rise to no pain at the time of its application, while the consequent suppuration is not in most cases more irksome to the patient than the prolonged and acute pain that attends the use of the usual caustics. 2. Permanent loss of hair does not result. 3. The treatment is easy to carry out. 4. Many intractable cases rapidly mend when so dealt with. 5. The agents employed are not poisonous.

I usually prescribe salicylic acid as an ointment of from ten to forty grains of the acid to an ounce of lard, vaseline, etc., and I often find advantage from combining it with other drugs, as carbolic acid or oil of cade, etc. If it be desired to increase its irritating properties, the addition of a few grains of perbromide of mercury or antimony chloride to the ointment will be effectual. Again, if an eczematous state of skin have supervened, some of the more soothing of the salts of zinc or mercury may be advantageously ordered with the salicylic acid. If a liquid form is preferred, from twenty to forty grains of salicylic acid may be dissolved in an ounce of alcohol and the affected parts painted with the solution two or three times a-day. Such solutions often set up much skin irritation.

The following cases of tinea tondens, which I have selected from among my notes, will serve to elucidate the action of croton oil and salicylic acid in the treatment of this disease. They were instances of tinea tondens affecting the scalp. Fungus was present in each, and none are noted as "well" till fungoid growth was unable to be discovered.

CASE I.-Henry C., aged $7 \frac{1}{2}$, was admitted at the Hospital for Diseases of the Skin, Blackfriars, on August 14th, 1878. The disease was first noticed in November 1877. Nearly the whole scalp was occupied by well marked ringworm. He was treated by ordinary methods till October 9 th, 1878, under the use of which the disease had become limited to one large patch on the vertex. On October 9th, $\mathbf{1 8 7 9}$, linimentum crotonis was applied to the patch. On November 6th, slight suppuration had resulted. Linimentum crotonis was reapplied. Salicylic acid ointment (twenty grains to one ounce) was applied night and morning. On November 2oth, he was improved. On December I 8 th, no evidence of the disease could be detected. He remained under observation till January 3 Ist, 1879 .

CASE II.-George P., aged 6, came under treatment on July Ioth, 1876. The disease commenced in the previous May. There was a pronounced patch of ringworm on the left temple. He was treated with cantharides, tar, etc., till October 9th. He was improved, but still infected. Linimentum crotonis was now painted over the affected parts. On October 3oth, suppuration had resulted. On November I 3 th, a portion of the patch showed disposition to scale. I reapplied the croton-oil liniment. On November 27 th, remains of inflammatory action were visible. On December I Ith, he was "well".

CASE. III.-Henry P., aged 6, came under my care on September 18th, 1878. Ringworm commenced about Christmas 1877. There were bare and scaly patches on the occiput. His sister was also affected. On October r6th, no improvement had followed the usual methods of treatment. I applied linimentum crotonis to the diseased parts. On October 23rd, the affected portions were inflamed and encrusted. Linimentum crotonis was repeated. The same application was made to the little girl. On October 3oth, in the little girl's case, some of the parts to which the liniment was used had suppurated. On December

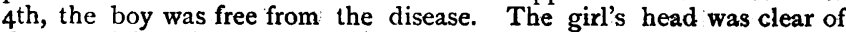
the complaint where suppuration had taken place. Salicylic acid oint- ment was ordered. On January 15 th, 1879 , there was no sign of the disease; nor on March Ioth.

CASE IV.- Grace P., aged 7, had three large spots of tinea tondens, of two months' duration, on the head. Her brother had the same complaint. She was treated by the ordinary methods for two months, with some slight improvement. On January 17 th, 1879 , linimentum crotonis was used, and salicylic acid ointment and cod-liver oil ordered. On February 26th, the old spots were "well", but two new ones had appeared. The treatment was repeated. On March 12th, she was "well".

CASE V.-Charles W., aged $7 \frac{1}{2}$, had ringworm over the greater part of the scalp since September 1878 . He was treated by a medical man with acetic acid and an ointment of sulphur and carbolic acid. On November 5 th, 1878 , linimentum crotonis was applied to scme of the spots. Salicylic acid ointment was used night and morning. On January 6th, 1879, there was no evidence of the disease.

CASE VI.-Eleanor B., aged $4 \frac{1}{2}$, had a well marked patch of tinea. tondens, about an inch and a half in diameter, on the vertex, and several smaller spots, of four weeks' duration. A brother and sister were similarly affected. On January 2oth, 1877, linimentum crotonis and salicylic acid ointment were ordered. On February Ioth, the parts were thickly crusted. On March Ioth, the parts previously affected were well, but a fresh spot had shown itself on the neck.

CASE VII.-Marion S., aged 6, had thickly encrusted ringworm of the entire scalp in an active state. The duration of the attack had been six weeks. She had been previously treated. On January 2oth, 1877, salicylic acid ointment was ordered. On January 29th, the scalp was irritated. On February I2th, kerion had formed. On March I2th, no tinea tondens could be detected; nor on March 26 th.

CASE VIII.-M. B., aged 7, had a large patch of ringworm on the head, with eight smaller ones. On January 27 th, 1877, linimentum crotonis was applied to the spots; salicylic acid ointment night and morning. On February Ioth, the treatment was repeated. On February 24 th, all the spots were suppurating slightly. On March 17 th, the skin was red. There were a few scales. No fungus was found.

CASE 1X.-H. D., aged 2, had three large spots of well marked tinea tondens on the head, with numerous disorganised hairs. The disease began about Christmas 1878 . There had been no antecedent treatment. On March 19th, 1879, salicylic acid ointment was ordered to be used night and morning. On April 2nd, the patient was better; and on April 23rd, "well". On April 3oth, there was no recurrence.

CASE X.-George W., aged 14, came under treatment, on April I6th, 1879, with ringworm on the occiput. The duration of this case was one month. The ordinary treatment was pursued. On June 4th, there was no improvement. I applied croton-oil liniment, and ordered ointment of salicylic acid. On June 16th, the parts had suppurated: On July I 4 th, he was apparently well.

Recent ringworm in healthy individuals, or on parts of the body not covered with thick hair, generally yields readily to any of the parasiticides in common use. I therefore reserve these more severe measures for the cases in which the disease has become firmly rooted. If a tendency to eczema or scalp-irritation exist, a less active treatment is preferable.

Cases of tinea tondens often suffer a relapse, the disease reappearing after an interval. Such an accident can be avoided by careful and constant inspection, and by the long continued use of some mild antidote. The extension of the disease must also be guarded against. The free application over the surrounding healthy skin of whatever parasiticide is selected will generally act as a preventative. Owing to the necessity of so free and prolonged an use of the remedies, non-poisonous substances are to be preferred.

In almost all the instances in which tinea tondens is chronic and intractable, the nutrition of the patient is defective. They are generally anæmic and thin, with feeble digestion and little inclination for fatty foods. The local treatment should therefore be supplemented by measures for the improvement of the constitutional condition. Fresh air ; the addition to the diet of fatty substances, as cod-liver oil, cream, etc.; the regulation of the digestion; attention to the action of the bowels; and the administration of tonics are generally called for.

The following points seem, then, to be worthy of consideration in the reatment of ringworm.

I. The risk of the extension of the disease should be avoided.

2. Suitable constitutional treatment should be adopted.

3. Recent cases in healthy individuals may be very well dealt with by almost any of the usual remedies.

4. In chronic and obstinate cases, the production of suppuration by croton-oil liniment, followed by the application of salicylic acid either alone or in combination (or of any agents whose action is similar), offers a not unpromising means of eradicating the disease. 